\title{
Crustal magma plumbing within a segment of the Mid-Atlantic Ridge, $35^{\circ} \mathrm{N}$
}

\author{
Laura S. Magde ${ }^{\mathrm{a}, *}$, Andrew H. Barclay ${ }^{\mathrm{a}, 1}$, Douglas R. Toomey ${ }^{\mathrm{a}}$, \\ Robert S. Detrick ${ }^{b}$, John A. Collins ${ }^{b}$ \\ a Department of Geological Sciences, University of Oregon, Eugene, OR 97403, USA \\ b Woods Hole Oceanographic Institution, Woods Hole, MA 02543, USA
}

Received 31 March 1999; accepted 4 November 1999

\begin{abstract}
We report the results of a seismic tomography experiment which images the three-dimensional nature of the crustal melt delivery system beneath a segment of the slow-spreading Mid-Atlantic Ridge. In the lower crust ( $>3.5 \mathrm{~km}$ depth) near the segment center, inversion of first-arriving crustal P-waves reveals a pair of vertical pipe-like $(<10-\mathrm{km}$ diameter) low-velocity anomalies $(-0.4 \mathrm{~km} / \mathrm{s})$. In the upper crust, these two features, which are physically isolated from each other below $3 \mathrm{~km}$, both connect to a $10-\mathrm{km}$-wide, $45-\mathrm{km}$-long, axis-parallel, low-velocity zone $(-0.2 \mathrm{~km} / \mathrm{s})$. Three higher-amplitude low-velocity anomalies $(-0.6 \mathrm{~km} / \mathrm{s})$ are observed in the upper crust $(<2 \mathrm{~km} \mathrm{depth})$, and are located directly beneath seafloor volcanic features. We interpret the overall image to represent the thermal/melt signature of a magma feeding system in which focused injections of magma from the mantle travel upward until they intersect the brittle-ductile transition, where they are then diverted along-axis to supply shallow intrusive bodies and seafloor eruptions along much of the ridge segment. (C) 2000 Elsevier Science B.V. All rights reserved.
\end{abstract}

Keywords: mid-ocean ridges; oceanic crust; magmatism; seismic methods; tomography

\section{Introduction}

At slow-spreading ridges such as the Mid-Atlantic Ridge (MAR), along-axis variations in crustal thickness, both inferred from gravity data [13] and measured seismically [4-8], confirm that crustal accretion is axially variable with increased

\footnotetext{
* Corresponding author. Fax: +1-541-346-3692;

E-mail: laura@cs.uoregon.edu

1 Present address: Woods Hole Oceanographic Institution, Woods Hole, MA 02543, USA.
}

melt flux near the centers of individual spreading segments $[9,10]$. These observations may be explained by a variety of mantle flow/melt extraction models [1,2,11-15] which share a common prediction that the time-averaged magma flux is focused at depths below the Moho and preferentially delivered to the center of each segment. However, previous studies have not addressed whether magma, which is initially focused toward the segment centers, is redistributed at crustal depths. We present the first three-dimensional images of a crustal magma plumbing system beneath a slow-spreading ridge, extending from a region of focused melt flux in the lower crust, to a more 
distributed pattern in the mid-to-upper crust, and finally to intrusions beneath individual volcanic features. On the basis of our results, we conclude that the characteristics of the magma plumbing system at crustal levels are governed by the interactions between ascending magma and tensional lithospheric stress.

\section{Study area}

In November 1996, we conducted a seismic Pwave tomography experiment, centered on a wellstudied segment of the MAR (Fig. 1). The study area is a $50 \times 44 \mathrm{~km}^{2}$ region covering the central section of the $90-\mathrm{km}$-long spreading segment, bounded to the north by the Oceanographer transform and to the south by a 35-km-long non-transform offset. Near its center, this segment displays shallow axial depths, a poorly developed rift valley, several near-axis seamounts [16], recent volcanism [16], a large gravity anomaly low [3] and thickened crust $[4,7,8]$. A previous microearthquake and upper-crustal tomography experiment also revealed a relatively shallow inferred depth to the brittle-ductile transition $(3-4 \mathrm{~km})$ [17] and an upper-crustal magma body beneath a near-axis seamount [18]. These characteristics have been attributed to a high heat flux, resulting in elevated crust and mantle temperatures, and thus a thin lithosphere [2,19]. The center of the $35^{\circ} \mathrm{N}$ segment therefore typifies a 'hot' section of a slow-spreading ridge.

Our experiment used nine ocean bottom hydrophones to record 2684 airgun shots (Fig. 1). The seismic source was the 20 -gun, $8495 \mathrm{cu}$. in. airgun array of the $R / V$ Ewing. The experimental geometry provides good three-dimensional ray coverage and identifiable arrivals at source-receiver ranges as large as $45 \mathrm{~km}$. Our analysis includes delay times from 16766 crustal P-wave arrivals (hand picked). Sample record sections are shown in Fig. 2. These two cross-axis record sections show the data quality and character in two contrasting locations: where the crust is relatively thick (Fig. 2a) and where it is relatively thin (Fig. 2b). In both record sections, the first-arriving crustal $(\mathrm{Pg})$ phases can be confidently picked out to where they are overtaken by the mantle refraction (Pn) phase (at $42 \mathrm{~km}$ where the crust is thick in the center of the segment, and at $27 \mathrm{~km}$ where the crust is thinner to the south). Only arrivals which turn within the crust $(\mathrm{Pg})$ are used in the current analysis. The record sections also show the contrast between the unattenuated arrivals at the southern end of the study area (Fig. $2 b)$ and the attenuated arrivals for ray paths traveling though the lower crust in the segment center (Fig. 2a). The Pg data provide three-dimensional ray coverage down to depths of $5.5 \mathrm{~km}$ below the seafloor, but do not penetrate the moho which occurs at a depth of $6-8 \mathrm{~km}$ in this region [7].

\section{Tomographic method}

We use a non-linear tomographic method [20] to invert first-arriving P-wave travel times for the isotropic velocity structure. For the forward problem, the seismic velocity model is defined within a $50 \times 44 \times 6 \mathrm{~km}^{3}$ volume at intervals of $250 \mathrm{~m}$ and $200 \mathrm{~m}$ in the horizontal and vertical directions, respectively. The ray-tracing method includes the effects of seafloor relief by shearing the grid vertically and, further, by interpolating the ray-entry points onto a $100 \mathrm{~m}$ grid (see references [18,20] for details). Estimated uncertainties include: ray tracing within the crust $(5 \mathrm{~ms})$, shot/receiver posi-

Fig. 1. Geometry of the tomographic experiment. The locations of the nine ocean bottom hydrophones (squares) and 2684 airgun shots (small dots) are shown. Bathymetry is contoured at $200 \mathrm{~m}$, with grayscale changes every $400 \mathrm{~m}$. The location of the NW axial ridge is indicated by the dashed white line and the positions of the $36^{\circ} 23^{\prime} \mathrm{W}$ and $36^{\circ} 28^{\prime} \mathrm{W}$ volcanoes are shown. The experimental coordinate system is rotated clockwise $15^{\circ}$ with respect to north and its origin is at $34^{\circ} 52.5^{\prime} \mathrm{N}$ and $36^{\circ} 25.0^{\prime} \mathrm{W}$. The shots and receivers included in the central (Fig. 2a) and southern (Fig. 2b) record sections are shown in white. Inset: The study area is a $50 \times 44 \mathrm{~km}^{2}$ region covering the central section of the $90-\mathrm{km}$-long spreading segment. Contour interval is $800 \mathrm{~m}$. Spreading is perpendicular to the trend of the axial valley with a half-rate of $\sim 1.2 \mathrm{~cm} /$ year [35]. This segment displays an hourglass-shaped rift valley, with along-axis topographic relief of $1.5-2 \mathrm{~km}$ between the segment midpoint and segment ends. 
tion $(6 \mathrm{~ms})$ calculated from the water-wave relocation algorithm (method described in reference [21]), bathymetry at the ray-entry points $(5 \mathrm{~ms})$, and arrival time picking (15 ms), resulting in a prior root-mean-squared (RMS) uncertainty of $18 \mathrm{~ms}$ for the travel-time data. See [18] for a more detailed discussion of estimating errors.

The inversion method uses a separate perturba-

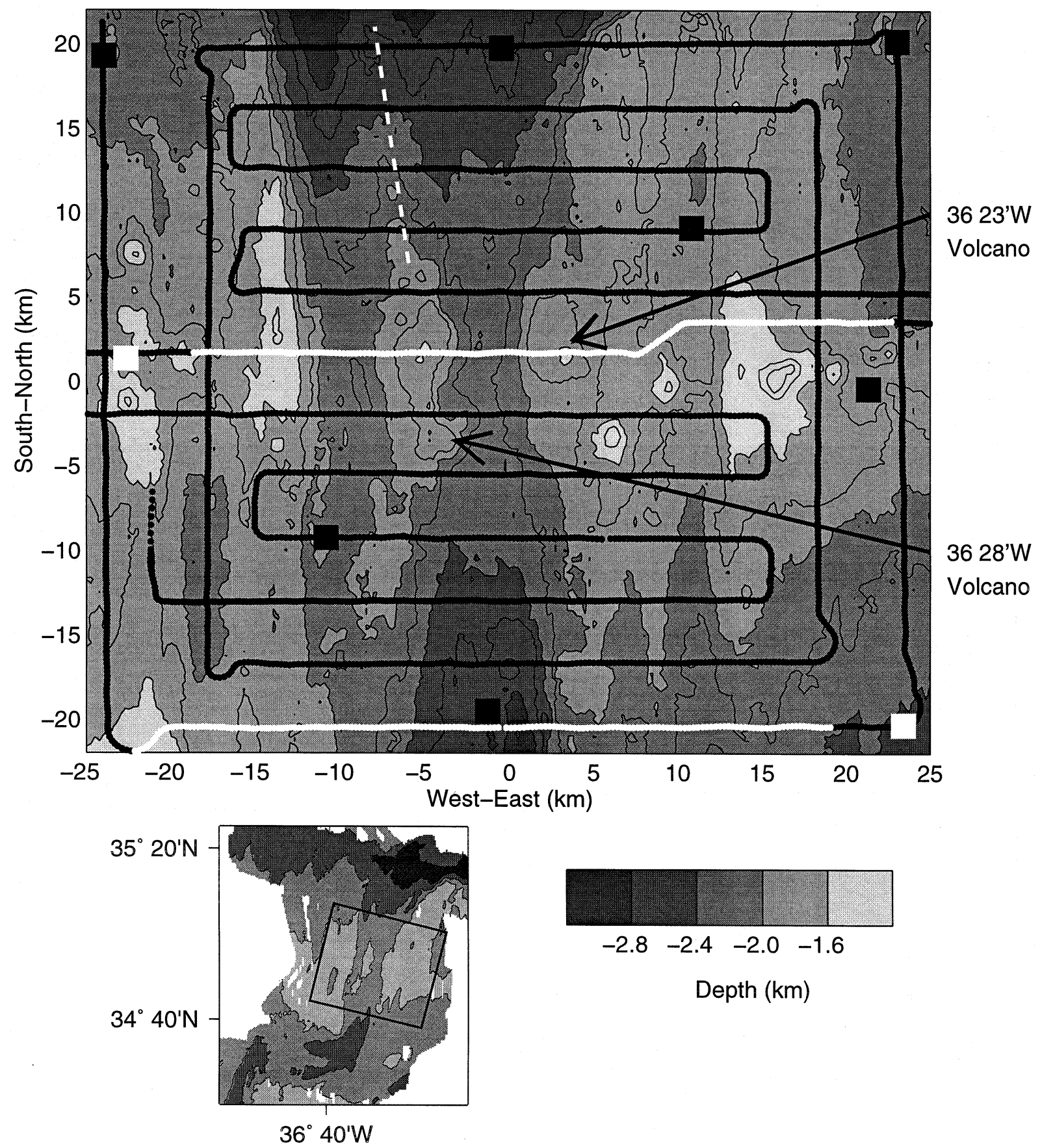


a)

Cross-Axis Record Section, $y=2$ km

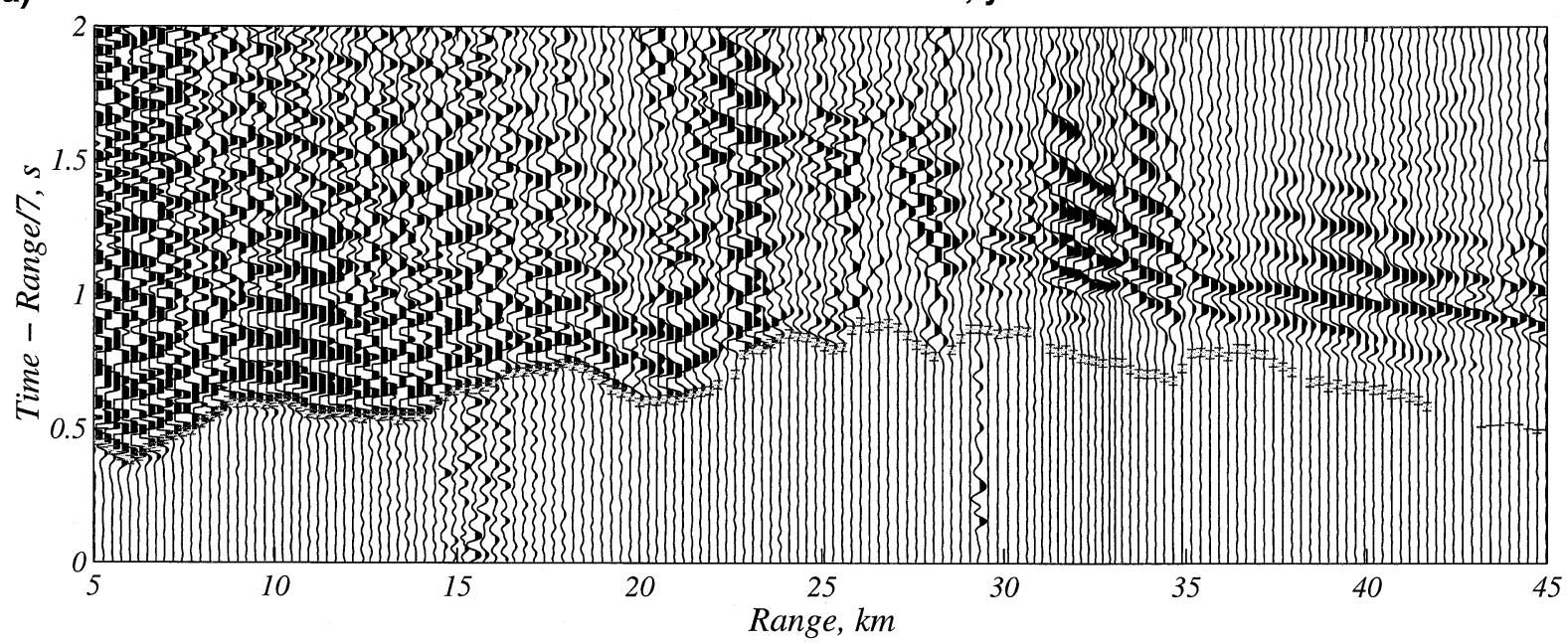

b)

\section{Cross-Axis Record Section, $y=-20$ km}

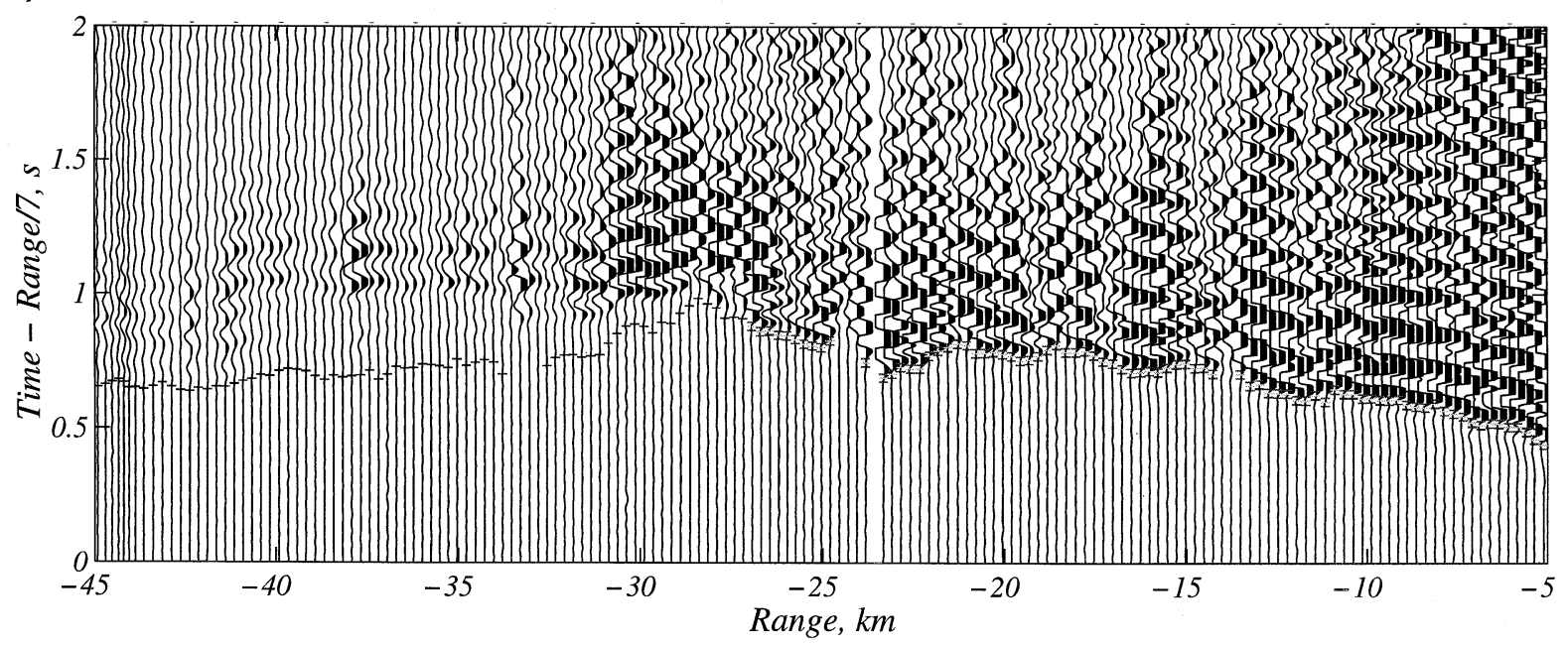

Fig. 2. Rise-perpendicular record sections. Locations of profiles are shown in Fig. 1. Each section has been corrected for topography and plotted with a reduced velocity of $7 \mathrm{~km} / \mathrm{s}$. Crustal refraction $(\mathrm{Pg})$ picks used in the analysis are shown in gray, with 15 ms (one standard deviation) uncertainties shown. At greater ranges the first-arriving phase is the mantle refraction (Pn), shown in black with no error bars, which were not included in the present analysis. Ranges are positive to the east. a: A cross-axis record section in the central portion of the segment where the crust is thick ( $\sim 8 \mathrm{~km}[7]) ; \mathrm{Pg}$ first arrivals extend to $42 \mathrm{~km}$ range. Note that the amplitude of the first arrival is attenuated at ranges greater than $\sim 24 \mathrm{~km}$, consistent with a low-velocity region beneath the center of the segment. b: A cross-axis record section at the southern edge of the experimental region where the crust is relatively thin ( $\sim 6 \mathrm{~km}$ [7]); crustal arrivals only extend to $27 \mathrm{~km}$ in range. In comparison with a, the arrivals are not attenuated.

Fig. 3. Results of tomographic inversion. a: Best-fit one-dimensional velocity model used as the reference model for all three-dimensional solutions. b-f: Map views (depths are indicated) of velocity anomalies in the preferred solution, relative to the one-dimensional starting model (reference velocity is indicated at each depth). $\mathrm{g}-\mathrm{j}$ : Vertical cross-axis sections at the indicated $y$-coordinate. The results of the inversion are masked out in regions where the derivative weight sum [20] (a measure of ray coverage) is less than 5 . Contour interval is $0.2 \mathrm{~km} / \mathrm{s}$. 
a)

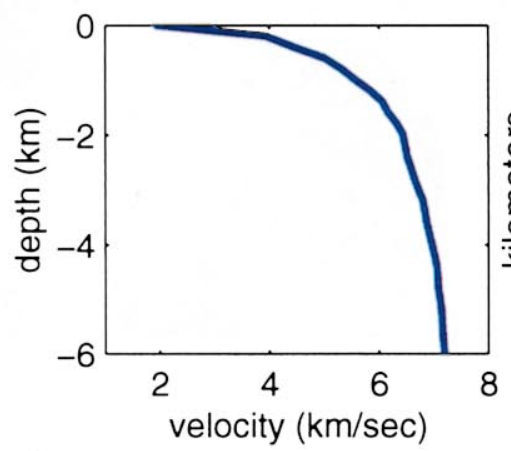

d)

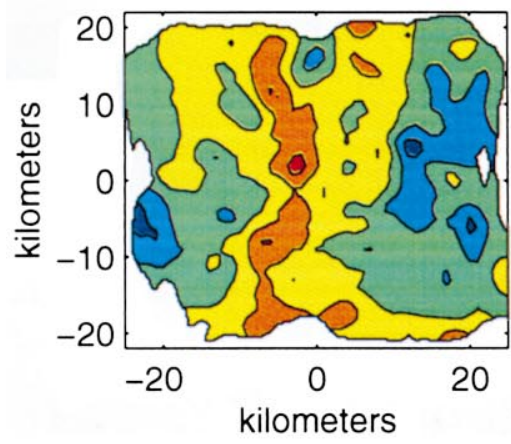

b)

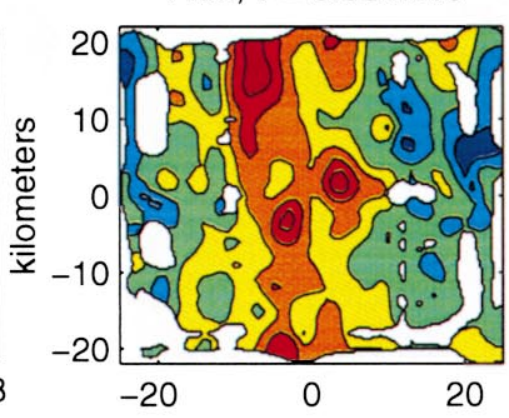

e)

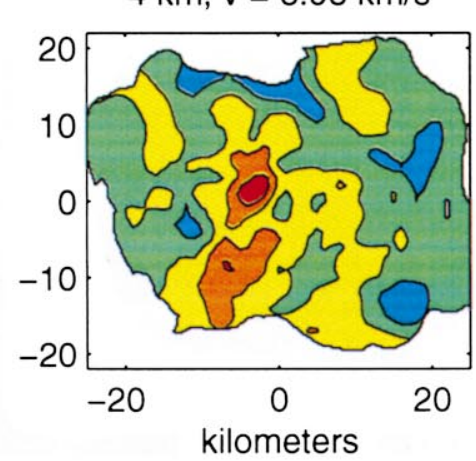

c)

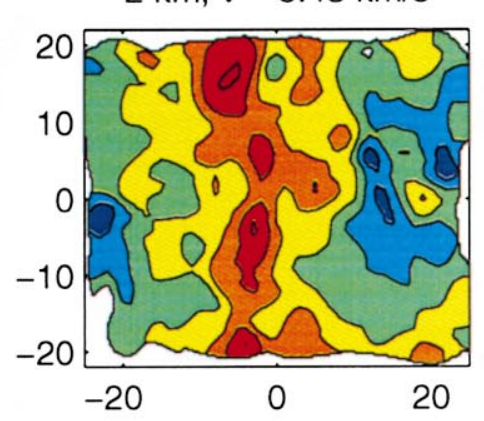

f)

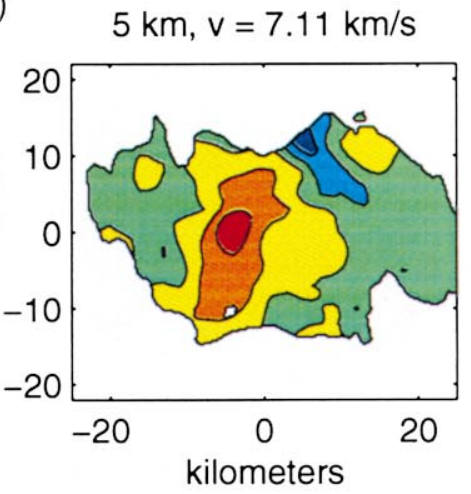

g) $\quad \mathrm{X}$-section at $15 \mathrm{~km}$

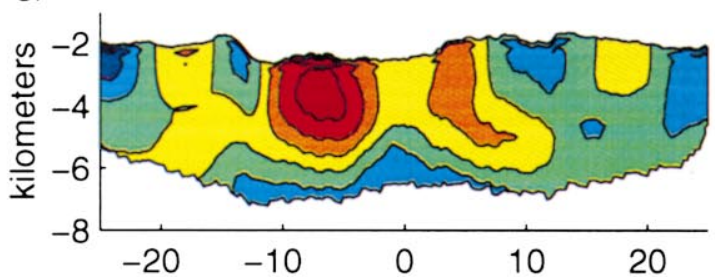

i)

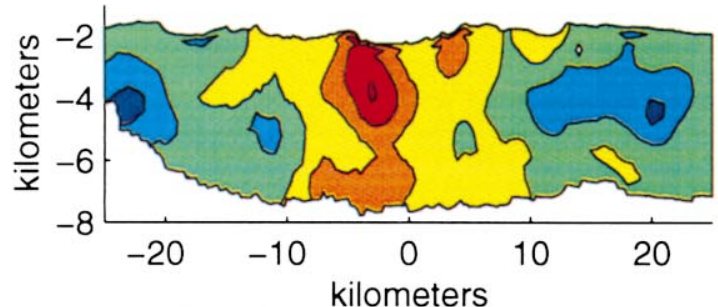

h)
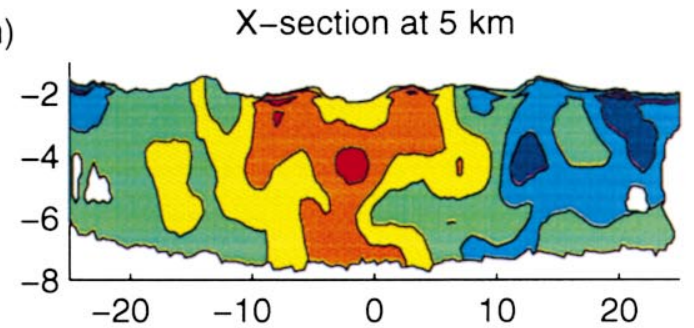

j)

X-section at $-15 \mathrm{~km}$

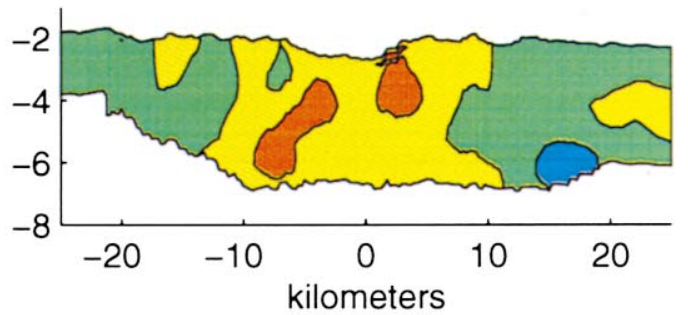

$$
\begin{array}{cccccc}
-.6 & -.4 & -.2 & 0.0 & 0.2 & 0.4 \\
& \text { Velocity Anomaly }(\mathrm{km} / \mathrm{s}) &
\end{array}
$$


tional model defined on a grid with $1 \mathrm{~km}$ horizontal and $400 \mathrm{~m}$ vertical spacing. The inverse problem is regularized by minimizing the model roughness at each iteration and a stochastic penalty function. The decay length of the smoothing operator is set at $110 \%$ of the interval between the perturbational nodes and the variance for a model parameter is $20 \%$. Inversions without the damping condition do not produce significantly different results.

The data are first inverted to obtain the bestfitting one-dimensional velocity model (Fig. 3a) which is then used as the starting model for all future inversions. For the three-dimensional solution, we invert the travel times under a variety of smoothing weights (over 40 individual inversions). For each set of conditions five iterations of the inverse problem are completed, at which point additional iterations do not result in a significant reduction in RMS travel-time residuals. (Based on an $\mathrm{F}$ test criterion, a change of $<1 \mathrm{~ms}$ is not significant at the $95 \%$ confidence level). In all cases the overall features are similar. None of the perturbations to the one-dimensional model are large enough to cause velocities to decrease with depth. Our preferred solution is the smoothest one which explains the data to the expected level of uncertainty, and results in an RMS reduction in travel-time residuals from $80 \mathrm{~ms}$ (the onedimensional solution) to $18 \mathrm{~ms}$.

\section{Results}

A prominent feature of the tomographic image (Figs. 3 and 4 ) is a $\sim 10$-km-diameter low-velocity anomaly $(-0.4 \mathrm{~km} / \mathrm{s})$ region near the segment center, and at depths greater than $4 \mathrm{~km}$ below the inner-valley floor. Lower-crustal velocities increase rapidly to the north, and somewhat less rapidly to the south, of this anomaly. Above $4 \mathrm{~km}$ depth a second narrow and sub-vertical ( $\sim 10$-km-diameter) feature is also resolved, still near the segment center, but slightly south of the first anomaly. Shallower than $3 \mathrm{~km}$ these low-velocity anomalies merge with an axis-parallel lowvelocity $(-0.2 \mathrm{~km} / \mathrm{s})$ band which approximately underlies, but is narrower than, the axial valley (Fig. 1). Above $2 \mathrm{~km}$ depth, three discrete lowvelocity anomalies $(-0.6 \mathrm{~km} / \mathrm{s})$ are observed. Two of these correlate with volcanoes located near $36^{\circ} 28^{\prime} \mathrm{W}$ and $36^{\circ} 23^{\prime} \mathrm{W}$ (Fig. 1). The third anomaly lies beneath an axis-parallel volcanic ridge referred to as the NW Axial Ridge (Fig. 1). These anomalies are much smaller in amplitude than the $-2.0 \mathrm{~km} / \mathrm{s}$ anomalies associated with the axial magma chamber at the East Pacific Rise [22].

\section{Resolution tests}

We have performed resolution tests to confirm that the data require the following features: a small-diameter, central, low-velocity anomaly at depths of $5 \mathrm{~km}$, an axis-parallel structure at depths less than $3 \mathrm{~km}$, and localized, low-velocity anomalies above $2 \mathrm{~km}$ depth which extend upwards to within $1 \mathrm{~km}$ of the surface. For each test, synthetic travel-time data were generated by three-dimensional ray tracing through a known velocity structure. Gaussian random noise with a standard deviation of $18 \mathrm{~ms}$ was added to the synthetic data. We then analyzed the synthetic data using the same initial velocity model and smoothing constraints as the preferred solution, to give the recovered velocity structures shown in Figs. 5 and 6.

Resolution tests show that lateral variations in the thickness of a near-surface, low-velocity $(\sim 2.5 \mathrm{~km} / \mathrm{s})$ layer (i.e. seismic layer $2 \mathrm{a})$ are de-

Fig. 4. Three-dimensional views of the crustal low-velocity anomalies. a: View is looking down on the model and toward the north-west. b: View is toward the east from a lower angle. The top of the tomographic image, above $1 \mathrm{~km}$ depth, has been removed to allow viewing of the shallow anomalies. The orange and red surfaces represent velocity anomalies of -0.3 and -0.5 $\mathrm{km} / \mathrm{s}$, respectively. A perspective view of the bathymetry is included and the vertical black lines show the association of the three upper-crustal anomalies with the $36^{\circ} 28^{\prime} \mathrm{W}$ and $36^{\circ} 23^{\prime} \mathrm{W}$ volcanoes and the NW Axial Ridge (see Fig. 1). 

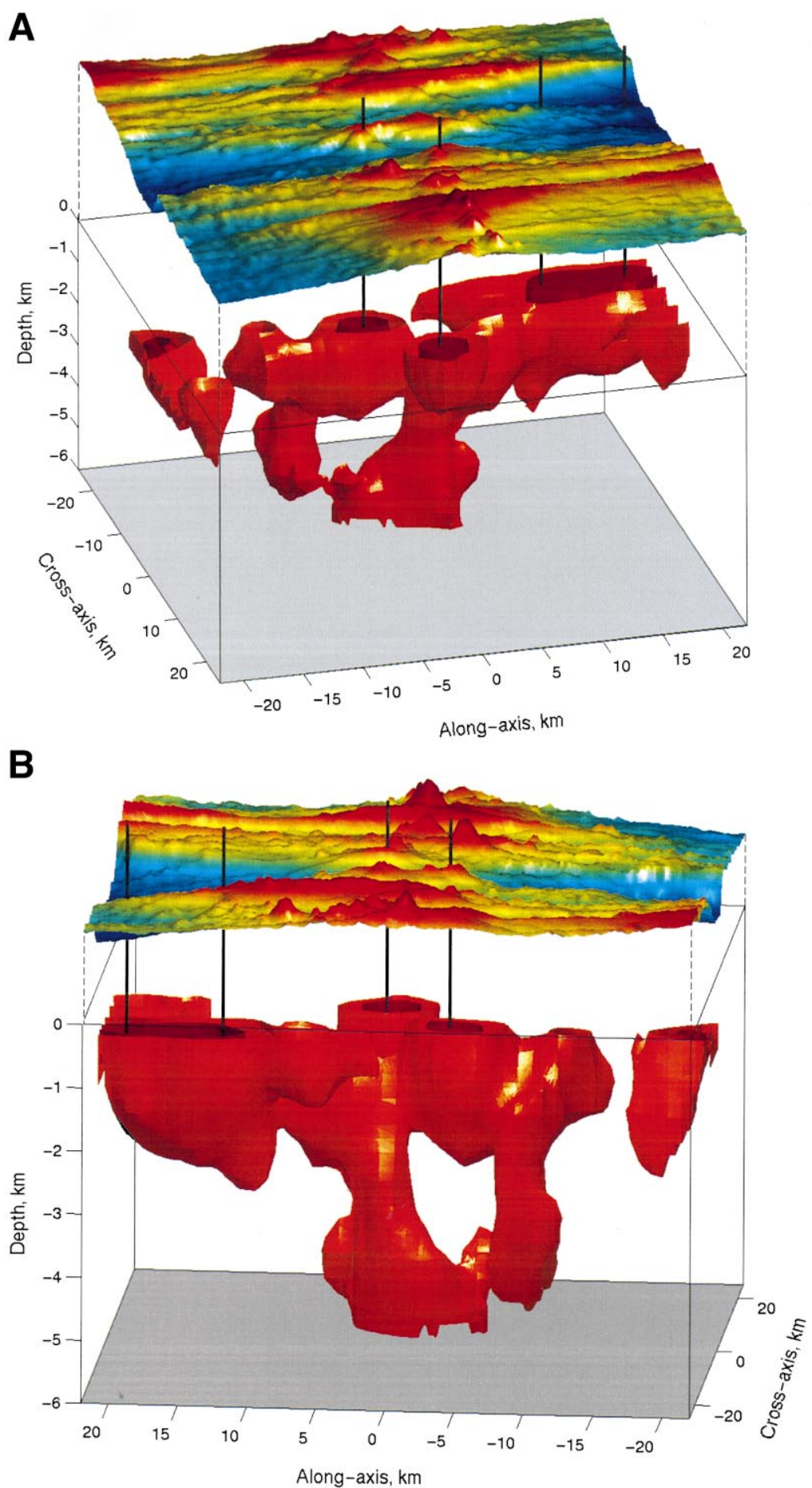


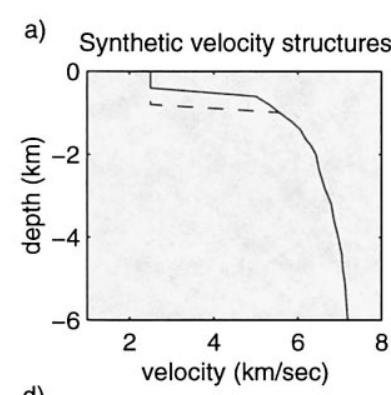

d)

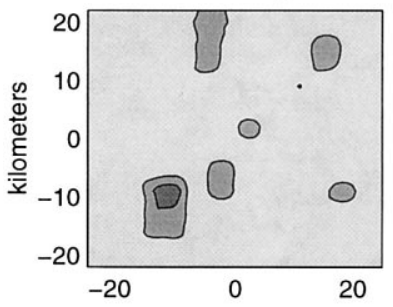

g)

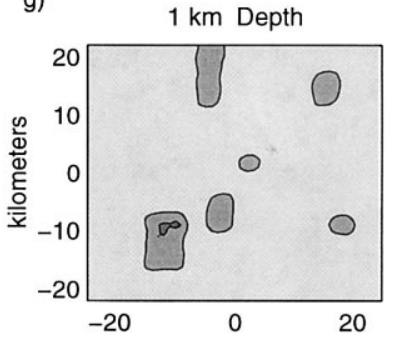

k)

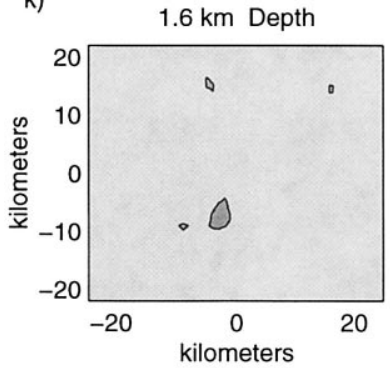

b)

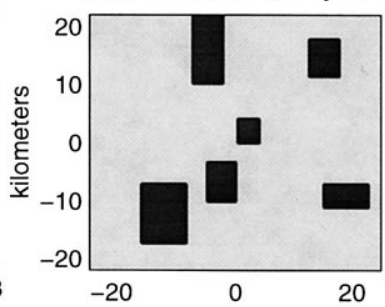

e)

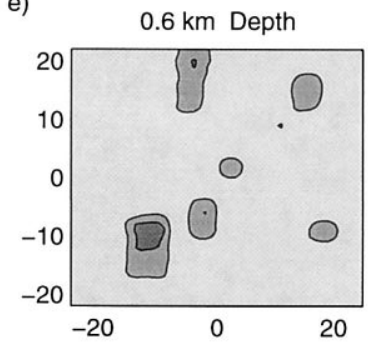

h)

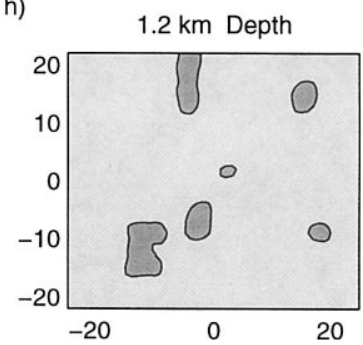

I)

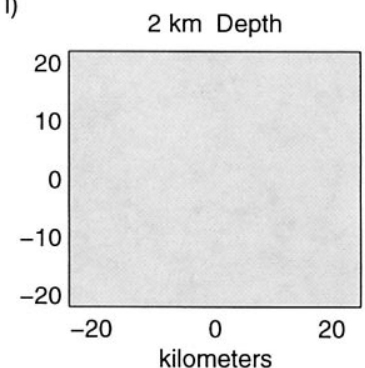

c)

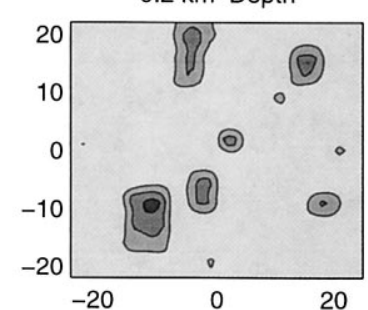

f)

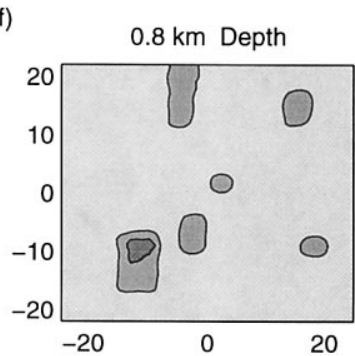

i)

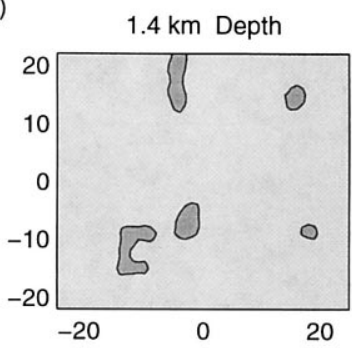

m)

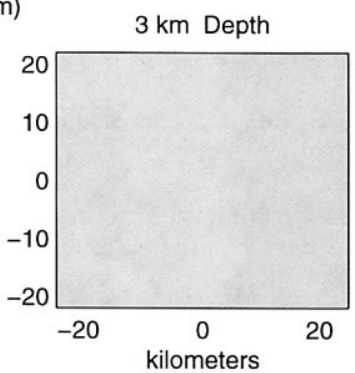

Fig. 5. Layer 2a resolution tests. Synthetic data were created for a velocity structure based on our best-fit 1d starting model (shown in Fig. 3a), modified to include a 400-m-thick layer $2 \mathrm{a}$ with a seismic velocity of $2.5 \mathrm{~km} / \mathrm{s}$ (the velocity jumps to $5.0 \mathrm{~km} / \mathrm{s}$ at the base of this surficial layer). The input velocity structure also included six patches (located both on and off axis) in which the layer thickness is doubled to $800 \mathrm{~m}$ (a). The input anomalies therefore have an amplitude of $-2.5 \mathrm{~km} / \mathrm{s}$ and extend from $400 \mathrm{~m}$ to $800 \mathrm{~m}$ depth. Horizontal slices through the recovered structure (achieved with our tomographic inversion procedure and a ray set identical to that of the actual data) show that the horizontal extent of the anomalies is well resolved, but they are smeared vertically, up to the surface and down to about $1.4 \mathrm{~km}$ depth. Contour interval is $0.2 \mathrm{~km} / \mathrm{s}$; darker grays indicate more negative anomalies. 

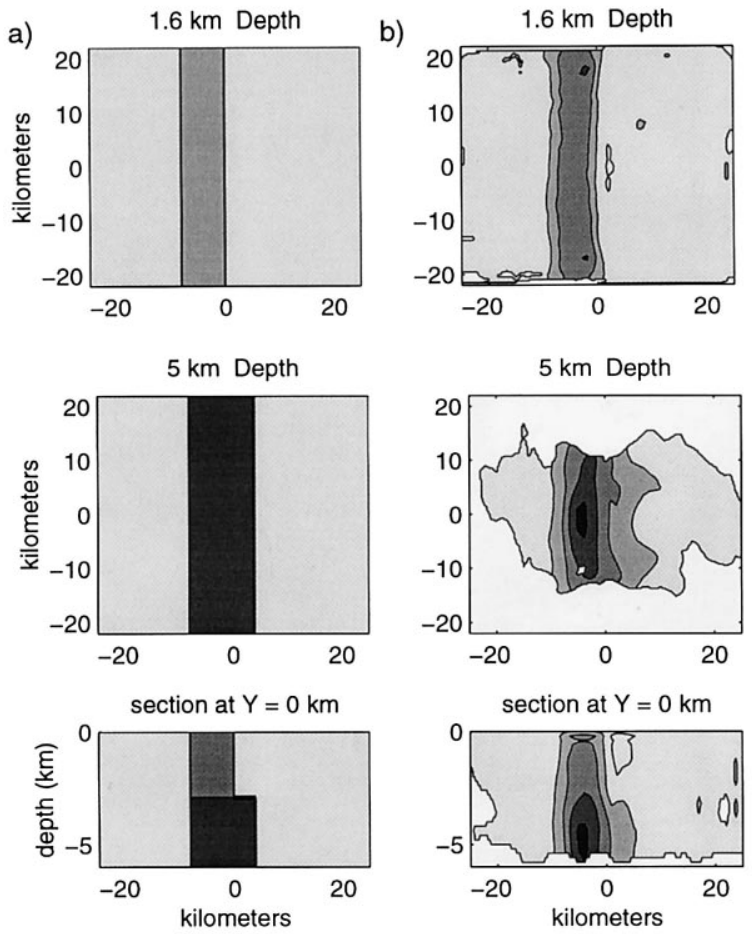

\section{Velocity Anomaly $(\mathrm{km} / \mathrm{s})$}
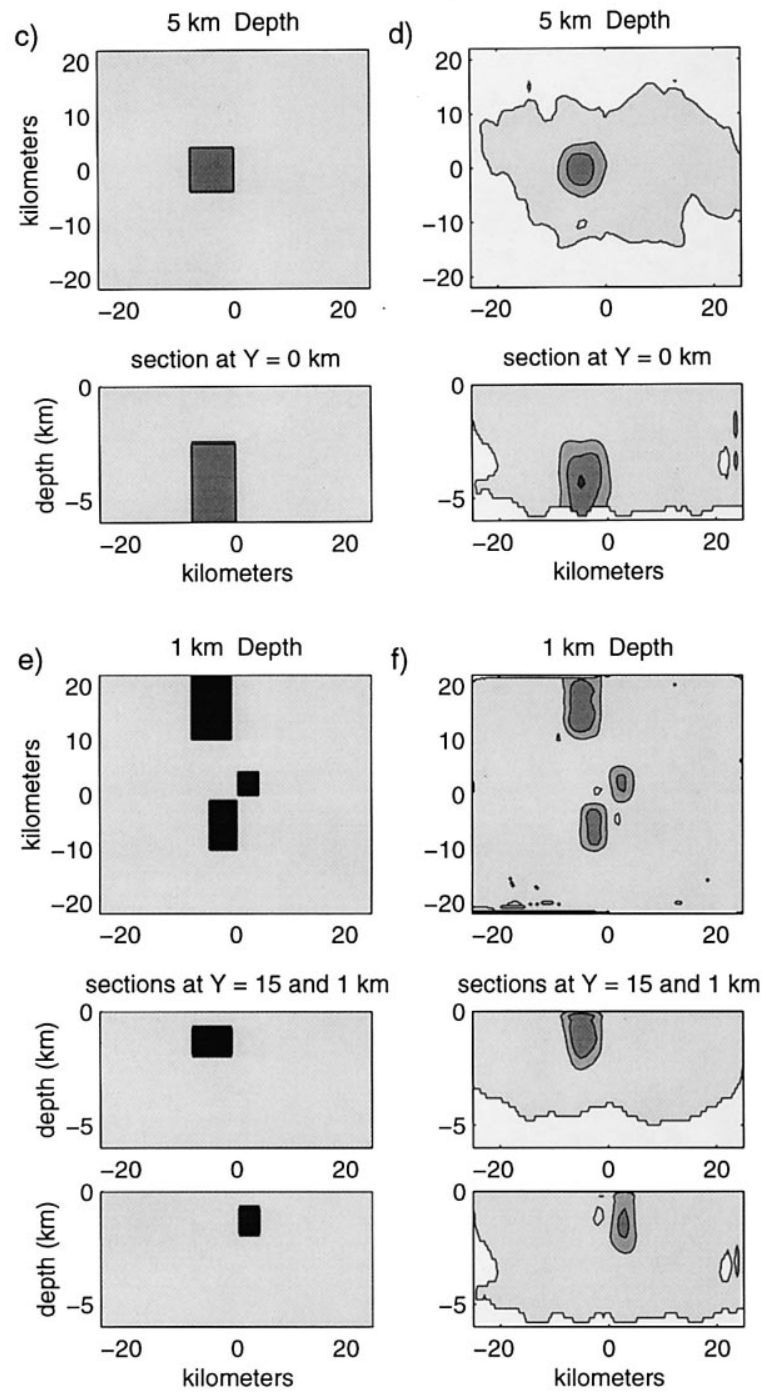

Fig. 6. Resolution tests. Each pair of figures includes the input velocity anomaly on the left (relative to the one-dimensional starting model in Fig. 3a) compared with that recovered using our tomographic inversion procedure and a ray set identical to that of the actual data. Contour interval is $0.2 \mathrm{~km} / \mathrm{s}$; darker grays indicate more negative anomalies. Test structures included: a: An upper-crustal low-velocity band of amplitude $-0.4 \mathrm{~km} / \mathrm{s}$ at depths $<3 \mathrm{~km}$ combined with a deep low-velocity band of amplitude $-0.6 \mathrm{~km} / \mathrm{s}$ at depths $>3 \mathrm{~km}$. b: Both anomalies are well recovered in amplitude and spatial extent. The upper along-axis band of anomalous velocities does not mask deeper axis-parallel structures. c: A deep, narrow anomaly of amplitude $-0.4 \mathrm{~km} / \mathrm{s}$. d: Both the amplitude and extent of the anomaly are well recovered, and can clearly be differentiated from an axially continuous anomaly. e: Shallow low-velocity volumes of amplitude $-1.2 \mathrm{~km} / \mathrm{s}$. Each volume extends from 0.8 to $2.0 \mathrm{~km}$ depth. f: The horizontal extent of each anomaly is well recovered, although we find that the anomalies are smeared downward by $\sim 500 \mathrm{~m}$ and upward to the seafloor. This is accompanied by an under-estimation of the anomaly magnitude by $>50 \%$ (maximum recovered amplitude is $-0.5 \mathrm{~km} / \mathrm{s})$. See text for further discussion. 
tectable given our ray set. Seismic reflection profiles in our study area have determined one-dimensional shallow (to depths of $800 \mathrm{~m}$ ) velocity structures for 11 locations, ranging in age from 0 to $1.9 \mathrm{Ma}$ [23]. Ray tracing through these structures we find a maximum 1-way variation of 20 $\mathrm{ms}$ for vertically propagating P-waves. Recognizing that these profiles may underestimate the regional variability in layer $2 \mathrm{a}$, we tested the sensitivity of our ray set to a much larger $(80 \mathrm{~ms})$ variation, corresponding to the doubling of layer 2a thickness from $400 \mathrm{~m}$ to $800 \mathrm{~m}$ (Fig. 5). The horizontal extent of layer $2 \mathrm{a}$ thickness variations is well resolved, a result consistent with previous tomographic studies which have imaged layer $2 \mathrm{a}$ [24]. Since our ray paths are near vertical in the shallow $(<1.5 \mathrm{~km})$ crust, the recovered anomalies are smeared vertically over this interval. Nonetheless, the largest velocity perturbations are confined to depths above $800 \mathrm{~m}$, and the maximum depth of velocity smearing is only $1.4 \mathrm{~km}$. If layer 2a thickness varies by $50 \%(200 \mathrm{~m})$ instead of $100 \%$, the recovered anomalies are unaffected below $1 \mathrm{~km}$ depth. Based on these results, we conclude that even relatively large variations $(400 \mathrm{~m})$ in seismic layer $2 \mathrm{a}$ thickness cannot explain the velocity anomalies we observe below $1-1.5 \mathrm{~km}$ depth.

Resolution in the lower crust $(>3 \mathrm{~km})$ is very good and is not affected by anomalous structures located at shallower depths (Fig. 6). We can clearly distinguish between a narrow, pipe-like feature and a deep, along-axis band of anomalous velocities (Fig. 6a-d). In the upper to middle crust $(1-3 \mathrm{~km})$, our horizontal resolution is also very good, and we can resolve anomalies of approximately $5 \mathrm{~km}$ diameter (Fig. 6e-f). As in the layer 2a tests (see Fig. 5) downward smearing of $\sim 500 \mathrm{~m}$ is observed, along with smearing upward to the surface. As a result, we can constrain the base of shallow (1-2 km depth) low-velocity anomalies to within $\sim 500 \mathrm{~m}$, but can only constrain the top of these anomalies to lie within $1 \mathrm{~km}$ of the surface.

Since tomography is a damped inversion technique, anomaly amplitudes are often underestimated. For the current data set, this phenomenon is prevalent in the shallow crust $(<2 \mathrm{~km}$ depth) where anomalies are aliased vertically. For example, compared to a study with a higher ray path density [18], the anomaly we recover beneath the $36^{\circ} 28^{\prime} \mathrm{W}$ volcano is lower in peak-to-peak amplitude $(-0.6$ compared to $-1.4 \mathrm{~km} / \mathrm{s})$ and broader ( $5 \mathrm{~km}$ east-west compared with $3 \mathrm{~km}$ ). Also, we have insufficient vertical resolution to differentiate between moderate-amplitude anomalies which extend throughout the upper crust $(-0.6 \mathrm{~km} / \mathrm{s}$ from 0 to $2.5 \mathrm{~km}$ depth) and higher-amplitude anomalies with a more limited vertical extent $(-1.2 \mathrm{~km} / \mathrm{s}$ but a depth range of only 0.8 to $2.0 \mathrm{~km}$ ). However, Barclay et al. [18] are able to place the top of the anomaly beneath the $36^{\circ} 28^{\prime} \mathrm{W}$ volcano in the top $1 \mathrm{~km}$ of the crust. By analogy, this suggests that the other upper-crustal $(<2 \mathrm{~km}$ depth $)$ anomalies we observe may be larger in amplitude and smaller in size, particularly in the vertical direction, than we have imaged.

\section{Interpretation}

Most of the observed low-velocity anomalies (Figs. 3, 4) are likely to be the result of anomalously high temperatures and/or small amounts of partial melt. For the higher-amplitude $(-0.6 \mathrm{~km} /$ s) anomalies in the upper crust $(<2 \mathrm{~km}$ depth), this interpretation invoking higher temperatures and/or retained melt is further suggested by the small size and ellipsoidal shape of the observed anomalies. The constraint that one of the anomalies does not reach the seafloor [18], the correlation of the three upper-crustal anomalies with localized, constructional, volcanic features, and their connection with low-velocity anomalies in the deeper crust also favor an interpretation that attributes the seismic anomalies to anomalously high temperatures and/or the presence of melt. This interpretation is not inconsistent with the observation of nearby microearthquakes [17], an occurrence which is often associated with volcanoes. For example, at the Krafla volcano in Iceland, microearthquakes are observed both above and below a crustal magma chamber [25].

We do note that $\mathrm{P}$-wave velocity reductions of -0.2 to $-0.6 \mathrm{~km} / \mathrm{s}$ can also be explained by porosity variations of $1-5 \%$, depending on the shape 
of the voids [26]. Therefore, cracks which close as crust moves off axis may explain the $-0.2 \mathrm{~km} / \mathrm{s}$ axial low-velocity band observed at approximately $3 \mathrm{~km}$ depth. However this $-0.2 \mathrm{~km} / \mathrm{s}$ velocity anomaly may also be explained by an axial temperature of $600^{\circ} \mathrm{C}$ (relative to $200^{\circ} \mathrm{C}$ slightly off axis as discussed below). Since $600^{\circ} \mathrm{C}$ is expected to be below the brittle-ductile transition [27], a thermal origin for the along-axis band is not inconsistent with the microearthquakes observed to depths of about $3.5 \mathrm{~km}$ [17]. Our data cannot differentiate between these two possibilities. However, while porosity may contribute to the $-0.2 \mathrm{~km} / \mathrm{s}$ axis-parallel low-velocity zone at $\sim 3 \mathrm{~km}$ depth, lithostatic pressure and ductile flow are likely to close cracks and pores in the lower crust. Consequently, the anomalies observed below about $3 \mathrm{~km}$ most likely have a ther$\mathrm{mal} / \mathrm{melt}$ origin.

To convert velocity anomalies to variations in temperature and melt, we assume a $\mathrm{P}$-wave velocity reduction of $-0.5 \mathrm{~m} / \mathrm{s} /{ }^{\circ} \mathrm{C}$ at temperatures below $1000^{\circ} \mathrm{C},-2.0 \mathrm{~m} / \mathrm{s} /{ }^{\circ} \mathrm{C}$ at temperatures above $1000^{\circ} \mathrm{C}$ (near the solidus) [28-29], and an upper-crustal ambient temperature of $200^{\circ} \mathrm{C}$ (an average of that calculated by Shaw and Lin [30] for depths shallower than $3 \mathrm{~km}$ at the center of a northern MAR segment). Anomalies of -0.3 and $-0.7 \mathrm{~km} / \mathrm{s}$ correspond to temperatures of 800 and $1150^{\circ} \mathrm{C}$ respectively. Since this highest temperature likely exceeds the solidus $\left(\sim 1100^{\circ} \mathrm{C}\right)$, a portion of the largest low-velocity anomalies $(-0.7$ $\mathrm{km} / \mathrm{s})$ in the upper ( $<2 \mathrm{~km}$ depth) crust is likely due to small amounts of partial melt. A supersolidus velocity reduction of $-0.2 \mathrm{~km} / \mathrm{s}$ requires $1-4 \%$ melt, depending on its distribution [31]. Since tomographic methods generally underestimate the amplitude of an anomaly, and our available ray set is prone to aliasing anomalies vertically in the shallow crust $(<1.5 \mathrm{~km}$ depth), all three of the upper-crustal $(<2 \mathrm{~km}$ depth) lowvelocity features we image may contain several percent partial melt. At depths of $5 \mathrm{~km}$, an ambient crustal temperature of $1000^{\circ} \mathrm{C}$ may be more appropriate [30]. Thus, even the relatively modest anomalies $(-0.4 \mathrm{~km} / \mathrm{s})$ observed in the middle to lower crust are consistent with small percentages of melt.

\section{Discussion}

We interpret our imaged velocity anomalies as representing a combination of increased temperatures and retained melt left behind by magmatic intrusions in a crustal magma plumbing system. In this view, Figs. 3 and 4 show a central region of current or recent lower-crustal magma injection which then spreads out along-axis at middle- and upper-crustal depths, to supply individual magma bodies and/or surface eruptions. The agreement between the depth of this transition (in the character of the low-velocity anomalies) and that of the inferred brittle-ductile transition $(\sim 3.5 \mathrm{~km}$ based on the maximum depth of observed microearthquakes [17]) suggests that the behavior of magmatic intrusions is controlled by crustal rheology. We propose that magma which is focused before reaching the lower crust then travels vertically through a ductile region in pipe-like features, following the high-temperature, low-strength pathway left by previous upwelling events. Upon reaching the base of the lithosphere, the magma interacts with extensional tectonic stresses and propagates along-axis through the brittle layer both laterally and vertically as dikes.

The continuity of the central low-velocity features with the mid-crustal ( $3 \mathrm{~km}$ depth) along-axis low-velocity anomaly suggests that this $44 \mathrm{~km}$ section of the ridge (and possibly the entire 90$\mathrm{km}$-long segment) is fed from a source region only $\sim 25 \mathrm{~km}$ wide. We infer that the northern central conduit feeds the central volcano near $36^{\circ} 28^{\prime} \mathrm{W}$, as well as the larger axial volcanic ridge to the north. The secondary conduit may similarly feed anomalies toward the south. We cannot rule out the possibility of lower crustal magmatic intrusions at other positions along the segment. However, since dikes at mid-ocean ridges have been observed to reach lengths of $60 \mathrm{~km} \mathrm{[32],} \mathrm{it} \mathrm{is} \mathrm{rea-}$ sonable to suggest that the entire segment could be fed from a single injection region located near the segment center. Such a system of magma injection may be similar to the central volcanoes observed in Iceland [33] and Hawaii [34].

The regions of anomalously low seismic velocity are unlikely to be the result of a single intrusion. Instead, we suggest that the low-velocity 
anomalies represent the time-integrated result of a number of injection episodes. Thus, if focusing of melt at mantle depths tends to homogenize magmas, our results indicate that upper-crustal intrusions may become chemically isolated in space or time. These intrusions may therefore undergo shallow fractionation and create a variety of basalt compositions before eruption onto the seafloor. Although we cannot address the question of solid-state mantle flow, our results are inconsistent with a hypothesis that crust is emplaced vertically at slow-spreading ridges. We provide evidence of enhanced magma flux at the center of an individual spreading segment, followed by along-axis magma transport at lithospheric depths, and conclude that observed variations in crustal thickness and structure are due, at least in part, to three-dimensional melt flow within the oceanic crust.

\section{Acknowledgements}

We would like to thank the officers and crew of the R/V Ewing, the WHOI OBS/OBH group, and members of the scientific party for their assistance in collecting this data set. We thank Robert Dunn for providing a parallelized version of the tomography code, and Marc Spiegelman and one anonymous reviewer for their suggestions. This work was supported by NSF grants EAR-9704657, OCE-9300450, EIA-9601801, and ACI-9522531.[CL]

\section{References}

[1] B.-Y. Kuo, D.W. Forsyth, Gravity anomalies of the ridge-transform system in the South Atlantic between 31 and $24.5^{\circ} \mathrm{S}$ : Upwelling centers and variations in crustal thickness, Mar. Geophys. Res. 10 (1988) 205-232.

[2] J. Lin, G.M. Purdy, H. Schouten, J.-C. Sempere, C. Zervas, Evidence from gravity data for focused magmatic accretion along the Mid-Atlantic Ridge, Nature 344 (1990) 627-632.

[3] R.S. Detrick, H.D. Needham, V. Renard, Gravity anomalies and crustal thickness variations along the Mid-Atlantic Ridge between $33^{\circ} \mathrm{N}$ and $40^{\circ} \mathrm{N}$, J. Geophys. Res. 100 (1995) 3767-3787.

[4] M.C. Sinha, K.E. Louden, The Oceanographer fracture zone - I. Crustal structure from seismic refraction studies, Geophys. J.R. Astr. Soc. 75 (1983) 713-736.

[5] G.M. Purdy, R.S. Detrick, Crustal structure of the MidAtlantic Ridge at $23^{\circ} \mathrm{N}$ from seismic refraction studies, J. Geophys. Res. 91 (1986) 739-3762.

[6] M.A. Tolstoy, J.A. Harding, J.A. Orcutt, Crustal thickness at the Mid-Atlantic Ridge: Bull's eye gravity anomalies and focused accretion, Science 262 (1992) 726-729.

[7] E.E.E. Hooft, R.S. Detrick, D.R. Toomey, J.A. Collins, J. Lin, Crustal thickness and structure along three contrasting segments of the Mid-Atlantic Ridge, $33.5-35^{\circ} \mathrm{N}$, J. Geophys. Res. (1999) in press.

[8] J.P. Canales, R.S. Detrick, J. Lin, J.A. Collins, D.R. Toomey, Crustal and upper mantle seismic structure beneath the rift mountains and across a non-transform offset at the Mid-Atlantic Ridge (35N), J. Geophys. Res. (1999) in press.

[9] H. Schouten, R.S. White, Zero-offset fracture zones, Geology 8 (1980) 175-179.

[10] H. Schouten, K.D. Klitgord, J.A. Whitehead, Segmentation of mid-ocean ridges, Nature 317 (1985) 225-229.

[11] J.A. Whitehead Jr., H.J.B. Dick, H. Schouten, A mechanism for magmatic accretion under spreading centres, Nature 312 (1984) 146-148.

[12] J.-C. Sempere, G.M. Purdy, H. Schouten, Segmentation of the Mid-Atlantic Ridge between $24^{\circ} \mathrm{N}$ and $30^{\circ} 40^{\prime} \mathrm{N}$, Nature 344 (1990) 427-431.

[13] D.W. Sparks, E.M. Parmentier, The generation and migration of partial melt beneath oceanic spreading centers, in: M.P. Ryan (Ed.), Magmatic Systems, Academic Press, New York, 1994, pp. 55-76.

[14] P.B. Kelemen, N. Shimizu, V.J.M. Salters, Extraction of mid-ocean-ridge basalt from upwelling mantle by focused flow of melt in dunite channels, Nature 375 (1995) 747 753.

[15] L.S. Magde, D.W. Sparks, R.S. Detrick, The relationship between buoyant mantle flow, melt migration, and gravity bull's eyes at the Mid-Atlantic Ridge between $33^{\circ} \mathrm{N}$ and $35^{\circ} \mathrm{N}$, Earth Planet. Sci. Lett. 148 (1997) 59-67.

[16] E. Gracia, D. Bideau, R. Hekinian, Y. Lagabrielle, Detailed geological mapping of two contrasting second-order segments of the Mid-Atlantic Ridge between Oceanographer and Hayes fracture zones $\left(33^{\circ} 30^{\prime} \mathrm{N}-35^{\circ} \mathrm{N}\right)$, J. Geophys. Res. 104 (1999) 22903-22921.

[17] A.H. Barclay, D.R. Toomey, G.M. Purdy, S.C. Solomon, Microearthquake characteristics and crustal Vp/Vs structure at the Mid-Atlantic Ridge, $35^{\circ}$ N, J. Geophys. Res., submitted.

[18] A.H. Barclay, D.R. Toomey, S.C. Solomon, Seismic structure and crustal magmatism at the Mid-Atlantic Ridge, $35^{\circ}$ N, J. Geophys. Res. 103 (1998) 17827-17844.

[19] P.R. Shaw, Ridge segmentation, faulting and crustal thickness in the Atlantic Ocean, Nature 358 (1992) 490 493.

[20] D.R. Toomey, S.C. Solomon, G.M. Purdy, Tomographic imaging of the shallow crustal structure of the East Pacific Rise at 9³0'N, J. Geophys. Res. 99 (1994) 24135-24157. 
[21] K.C. Creager, L.M. Dorman, Location of instruments on the seafloor by joint adjustment of instrument and ship positions, J. Geophys. Res. 87 (1982) 8379-8388.

[22] E.E. Vera, J.C. Mutter, P. Buhl, J.A. Orcutt, J.A. Harding, M.E. Kappus, R.S. Detrick, T.M. Brocher, The structure of 0 - to $0.2 \mathrm{~m}$.y.-old oceanic crust at $9^{\circ} \mathrm{N}$ on the East Pacific Rise from expanded spread profiles, J. Geophys. Res. 95 (1990) 15529-15556.

[23] S.A. Hussenoeder, R.S. Detrick, G.M. Kent, Upper crustal seismic structure of the slow spreading Mid-Atlantic Ridge, $35^{\circ} \mathrm{N}$ : Constraints on volcanic emplacement processes, J. Geophys. Res., submitted.

[24] D.R. Toomey, G.M. Purdy, S.C. Solomon, W.S.D. Wilcock, The three-dimensional seismic velocity structure of the East Pacific Rise near latitude $9^{\circ} 30^{\prime} \mathrm{N}$, Nature 347 (1990) 639-645.

[25] A.R. Sanford, P. Einarsson, Magma chambers in rifts, in: G. Palmason (Ed.), Continental and Oceanic Rifts, American Geophysical Union, Washington, DC, 1982, pp. 147168.

[26] R.H. Wilkins, G.J. Fryer, J. Larsten, Evolution of porosity and seismic structure of upper oceanic crust: Importance of aspect ratios, J. Geophys. Res. 96 (1991) 1798117995.

[27] G. Hirth, J. Escartin, J. Lin, The rheology of the lower oceanic crust: Implications for lithospheric deformation at Mid-Ocean Ridges, in: W.R. Buck, P.T. Delaney, J.A. Karson, Y. Lababrielle (Eds.), Faulting and Magmatism at Mid-Ocean Ridges, American Geophysical Union, Washington, DC, 1998, pp. 291-303.
[28] S. Karato, Importance of anelasticity in the interpretation of seismic tomography, Geophys. Res. Lett. 20 (1993) $1623-1626$.

[29] E.D. Humphreys, K.G. Dueker, Physical state of the western U.S. upper mantle, J. Geophys. Res. 99 (1994) 9635-9650.

[30] W.J. Shaw, J. Lin, Models of ocean ridge lithospheric deformation: dependence on crustal thickness, spreading rate, and segmentation, J. Geophys. Res. 101 (1996) 17977-17993.

[31] H. Schmeling, Numerical models on the influence of partial melt on elastic, anelastic and electric properties of rocks. Part 1: elasticity and anelasticity, Phys. Earth Planet. Int. 41 (1985) 34-57.

[32] R.P. Dziak, C.G. Fox, A.E. Schreiner, The June-July 1993 seismic-acoustic event at the coAxial segment, Juan de Fuca Ridge: Evidence for a lateral dike injection, Geophys. Res. Lett. 22 (1995) 135-138.

[33] P. Einarsson, B. Brandsdottir, Seismological evidence for lateral magma intrusion during the 1978 deflation of the Krafla Volcano in NE Iceland, J. Geophys. 47 (1980) 160 165.

[34] M.P. Ryan, R.Y. Koyanagi, R.S. Fiske, Modeling the three-dimensional structure of macroscopic transport systems: Application to Kilauea Volcano, Hawaii, J. Geophys. Res. 86 (1981) 7111-7129.

[35] K.D. Klitgord, H. Schouten, Plate kinematics of the central Atlantic, in: P.R. Vogt, B.E. Tucholke (Eds.), The Geology of North America, Geological Society of North America, Boulder, CO, 1986, pp. 351-387. 